\title{
Susceptibility of Different Populations of Tribolium confusum (Coleoptera: Tenebrionidae) to Malathion (EC 57\%) in Flour Mills of Iran
}

\author{
M. JAVADZADEH*, A. SHEIKHI-GARJAN and A. HOSSEINI-GHARALARI \\ Agricultural Entomology Research Department, Iranian Research Institute of Plant Protection, Agricultural \\ Research, Education and Extension Organization (AREEO), Yaman St., Chamran Hwy., Tehran, Iran
}

(Received: 22 August 2016; accepted: 07 September 2016)

\begin{abstract}
The confused flour beetle, Tribolium confusum, is a key pest of stored products such as wheat and flour. For decades, organophosphorus compounds, such as malathion and pirimiphos-methyl, have been applied against stored-product pests. In this research, susceptibility of different populations of $T$. confusum, collected from silos at different locations of Iran, against malathion (EC 57\%), was studied in the laboratory, based on a completely randomized design. Based on pre-tests, the Bioassay Index Dose was estimated as $2 \mathrm{~g}$ a.i./m2. Out of 23 populations, 2 populations from Bandar-Abbas region were resistant populations against malathion (9.72\% and $67.2 \%$ mortality), while one population from Khomein region was moderately resistant $(86.08 \%$ mortality), and the rest of the population were susceptible to malathion (95.71\% to $100 \%$ mortality). Therefore, in warm locations of Iran, where this pest has evolved resistance against malathion, other control measures shall be considered.
\end{abstract}

Keywords: bioassay, malathion, pests, stored-products, susceptibility.

The confused flour beetle, Tribolium confusum (Coleoptera: Tenebrionidae), is a key pest of stored-products such as wheat and flour, causing serious damage in silos especially in tropical and semi-tropical regions. This pest feeds on cereal grains, oil seeds, peanuts, cotton seeds, dried beans and macaroni (Bagheri Zenouz, 1986). Its damage results in reduction of flour quality (Songa and Rono, 1998).

For decades, organophosphorus compounds, such as malathion, pirimiphos-methyl and carbaryl, along with methyl-bromide have been applied against stored product pests in many countries. At present, in Iran, application of pirimiphos-methyl and carbaryl has been banned, and methyl-bromide will be banned in near future, which may result in increase of malathion application. It is best to not apply chemical insecticides in stored-product silos; however, sometimes it is necessary to control the insect pests in empty silos before filling them up.

There are several reports on emergence of biotypes of insect pests resistant to insecticides. For example, resistance of Red Flour Beetle, Tribolium castaneum (Coleoptera: Tenebrionidae) to different groups of insecticides (Ahuja, 1985; Halliday et al., 1988), resistance of different populations of Tribolium spp. to malathion in India (Jola

* Corresponding author; e-mail: mehranjd@yahoo.com 
and Chawla, 1988), resistance of different populations of Tribolium spp. to different groups of insecticides in Philippines (Calibosa et al., 1985) and resistance of different stored-product pests to pirimiphos-methyl, chlorpyrifos-methyl and carbaryl in U.S.A. (Beeman and Wright, 1990). Study on susceptibility of different populations of T. confusum to three different insecticides showed that teflubenzuron $\left(\mathrm{LC}_{50}=116.47\right)$ were the most toxic compound while pyriproxyfen $\left(\mathrm{LC}_{50}=307.04\right)$ were the least toxic compound. Moreover, this study revealed that the young larvae were more susceptible than 17-day old larvae (Loni et al., 2010).

The goal of this research was to collect different populations of T. confusum from wheat silos at different regions of Iran and study the susceptibility of these populations against malathion. The results would benefit the IPM managers in controlling this pest and reduce the control cost.

\section{Materials and Methods}

The larvae and adults of $T$. confusum were collected from wheat flour silos of the following regions: Bandar-Abbas (Hormozgan province), Arak (Markazi province), Khomein (Markazi province), Isfahan (Isfahan province), Qom (Qom province), Rasht (Gilan province), Gorgan (Goelstan province), Karaj (Alborz province), Urmia (West Azarbayjan province), Tabriz (East Azarbayjan province) and Ardabil (Ardabil province). The collected samples were reared on sterilized wheat flour in incubators $\left(28 \pm 2{ }^{\circ} \mathrm{C}\right.$, $65 \pm 5 \%$ R.H., 16:8 h L:D photoperiod). In this research, malathion (EC 57\%) (Bayer Co., Leverkusen, Germany) was applied in all tests.

In preliminary tests, three different doses $\left(1,2\right.$ and $4 \mathrm{~g}$ a.i. $\left./ \mathrm{m}^{2}\right)$ were applied against 2-day old adults, and mortality rates were estimated $24 \mathrm{~h}$ after application. Therefore, $11.15,22.77$ and $44.60 \mathrm{~g}$ of malathion (EC 57\%) was applied to Petri dishes $(9 \mathrm{~cm}$ in diameter) to reach the above-mentioned doses. The $4 \mathrm{~g}$ a.i. $/ \mathrm{m}^{2}$ dose resulted 100 percent mortality in all populations, while the $1 \mathrm{~g}$ a.i. $/ \mathrm{m}^{2}$ dose resulted less than $50 \%$ mortality in all populations; therefore, the $2 \mathrm{~g}$ a.i. $/ \mathrm{m}^{2}$ were chosen as the Bioassay Discriminating Dose (BDD). To reach the BDD, $2.277 \mathrm{~g}$ of malathion (EC 57\%) was added to $100 \mathrm{ml}$ of distilled water; next, $1 \mathrm{ml}$ of this solution was applied to the filter paper inside the Petri dish. For control treatment, distilled water was applied on the filter paper. There were 23 treatments (populations) and 4 replications which were studied based on a completely randomized design test. All tests was conducted in the laboratory $\left(28 \pm 2{ }^{\circ} \mathrm{C}, 65 \pm 5 \%\right.$ R.H., 16:8 h L:D photoperiod). Each replication included 50 2-day adults (25 male and 25 female). The insects were released on the filter paper when the treated filter papers were dried out completely. The morality rates were calculated $24 \mathrm{~h}$ later based on Abbott formula (Abbott, 1925). The mean morality rates were subjected to analysis of variance (PROC MIXED) followed by Tukey-Kramer $(\alpha=0.05)$ test in SAS 9.1 (SAS Inc., 2002). As, the Adrabil population ('Ard-e-Adabil') had the least treatment history, and also, as it showed $100 \%$ mortality at $2 \mathrm{~g}$ a.i. $/ \mathrm{m}^{2}$, it was chosen as the reference population for estimating the Resistance Index (RI), which was estimated by dividing the mortality rate of the reference population by mortality rate of each population. 


\section{Results and Discussion} (Table 1).

There was not any mortality at control of all populations, $24 \mathrm{~h}$ after treatment

The mean morality rates were significantly different among populations $24 \mathrm{~h}$ after treatment $\left(\mathrm{F}_{22,69}=126.69, \mathrm{P}<0.0001\right)$. The least mortality was observed in 'Ard-eKhatam' of Bandar-Abbas population $(9.72 \%)$, which was significantly different from other populations. It was followed by 'Ard-Sadaf' of Khatam population (67.2\%) and

\section{Table 1}

The mean $( \pm$ SE) percentage mortality of different populations of the confused flour beetle, Tribolium confusum, $24 \mathrm{hr}$ after treatment with malathion (EC 57\%)

\begin{tabular}{|c|c|c|c|c|}
\hline \multirow{2}{*}{ Collection location } & \multirow{2}{*}{ Flour company } & \multicolumn{3}{|c|}{ Mean mortality $\% \pm \mathrm{SE}$} \\
\hline & & control & insecticide & Resistance Index \\
\hline Arak & 'Ard-e-Sefid' & 0 & $100 \pm 0 \mathrm{a}^{*}$ & 1 \\
\hline Ardabil & 'Ard-e-Iran' & 0 & $100 \pm 0 \mathrm{a}$ & 1 \\
\hline Ardabil $\dagger$ & 'Ard-e-Ardabil' & 0 & $100 \pm 0 \mathrm{a}$ & 1 \\
\hline Urmia & 'Ard-e-Sepi' & 0 & $100 \pm 0 \mathrm{a}$ & 1 \\
\hline Urmia & 'Ard-e-Ferdos' & 0 & $100 \pm 0 \mathrm{a}$ & 1 \\
\hline Urmia & 'Ard-e-Bakhtar' & 0 & $100 \pm 0 \mathrm{a}$ & 1 \\
\hline Isfahan & 'Ard-e-Azadi' & 0 & $95.71 \pm 1.84 \mathrm{a}$ & 1.04 \\
\hline Isfahan & 'Ard-e-Motahari' & 0 & $100 \pm 0 \mathrm{a}$ & 1 \\
\hline Isfahan & 'Ard-e-Mahdi' & 0 & $100 \pm 0 \mathrm{a}$ & 1 \\
\hline Isfahan & 'Ard-e-Khabazan' & 0 & $100 \pm 0 \mathrm{a}$ & 1 \\
\hline Bandar-Abbas & 'Ard-e-Sadaf' & 0 & $67.2 \pm 6.88 \mathrm{c}$ & 1.48 \\
\hline Bandar-Abbas & 'Ard-e-Khatam' & 0 & $9.72 \pm 1.71 d$ & 10.3 \\
\hline Tabriz & 'Ard-e-Jahan' & 0 & $100 \pm 0 \mathrm{a}$ & 1 \\
\hline Tabriz & 'Ard-e-Iran' & 0 & $100 \pm 0 \mathrm{a}$ & 1 \\
\hline Tabriz & 'Ard-e-Setareh' & 0 & $100 \pm 0 \mathrm{a}$ & 1 \\
\hline Tabriz & 'Ard-e-Etehad' & 0 & $100 \pm 0 \mathrm{a}$ & 1 \\
\hline Khomein & 'Ard-e-Khomein' & 0 & $86.08 \pm 3.98 b$ & 1.16 \\
\hline Rasht & 'Ard-e-Boujar' & 0 & $100 \pm 0 \mathrm{a}$ & 1 \\
\hline Rasht & 'Ard-e-Shad' & 0 & $100 \pm 0 \mathrm{a}$ & 1 \\
\hline Qom & 'Ard-e-Qom' & 0 & $100 \pm 0 \mathrm{a}$ & 1 \\
\hline Karaj & 'Ard-e-Markazi' & 0 & $98.33 \pm 0.96 a$ & 1.02 \\
\hline Karaj & 'Ard-e-Tak' & 0 & $100 \pm 0 \mathrm{a}$ & 1 \\
\hline Gorgan & 'Ard-e-Gorgan' & 0 & $100 \pm 0 \mathrm{a}$ & 1 \\
\hline
\end{tabular}

$\dagger$ A strain from Ardabil which was selected as susceptible population

* Means in a column followed by the same letter were not significantly different based on Tukey-Kramer test $(\alpha=0.05)$ 
'Ard-e-Khomein' of Khomein population (86.8\%). The rest of the populations had 100\% mortality except 'Ard-e-Azadi' of Isfahan population (95.7\%) and 'Ard-e-Markazi' of Karaj population $(98.3 \%$ ) (Table 1).

The RI showed that 'Ard-e-Khatam'; of Bandar-Abbas population was 10.2 times resistant to malathion, followed by 'Ard-e-sadaf' of Bandar-Abbas population (1.48) and 'Ard-e-Khomein' of Khomein population (1.16) (Table 1).

There have been several research on application of discriminating dose for studying the susceptibility of insect populations to insecticides (Haubruge et al., 2002; Arnaud and Haubruge, 2002). The BDI kills more than $90 \%$ of treated population, while a population with less that $90 \%$ mortality is considered as 'resistant' or 'tolerant' population (Snodgrass, 1996; Snodgrass and Scott, 1999; Gordon and Snodgrass, 2008). The results of our study confirmed the ideas of other researchers that recommended considering a population resistant with les that $90 \%$ morality. Study of Ameri Tourzani et al. (2008) on Tribolium spp. showed that susceptibility of four populations ('Urmia', 'Varamin', 'Mashhad' and 'Karaj') were different when treated with malathion. Based on $\mathrm{LC}_{50}$, the 'Urmia' Population was 2.7 times more resistant than 'Varamin' population. Also, 'Karaj' population was more resistant than 'Varamin' population. Therefore, the result of our study is similar to Ameri Tourzani et al. (2008) confirming the low efficacy of malathion against Tribolium spp. in some of the silos of Iran. Our results along with other reports confirm the emergence of resistant biotypes of the flour beetles in wheat silos of Iran.

Haubruge et al. (2002) found that resistance of T. castaneum to malathion was due to increase in activity of malathion carboxylesterase enzyme up to 44 folds in the resistant population. Similar mechanism might have occurred in the Iranian populations.

There have been also some reports on resistance of Tribolium spp. populations to insecticides other than malathion. For example, Zettler (1991) found that among 17 populations of $T$. confusum, collected from different regions of U.S.A., resistance percentage against malathion, chlorpyrifos-methyl, dichlorvos and phosphine was $100 \%, 53 \%$, $24 \%$ and $18 \%$, respectively. Among 28 populations of T. castaneum, resistance percentage against malathion, dichlorvos and phosphine was $93 \%, 64 \%$ and $46 \%$, respectively. The similar result of the study in U.S.A. and our study recommend that application of malathion against Tribolium spp. shall be managed carefully and special methods for management of resistant biotypes shall be applied.

Due to high temperature in the southern parts of Iran, flour beetle has more generations per year compared to colder regions (Taheri, 1994). Therefore, silo managers in these regions apply more insecticides per year compared to other locations. This has resulted in emergence of resistant biotypes, similar to reports of other countries (White and Ben, 1988). It is recommended to change the management methods and protocol in wheat flour silos of tropical regions of Iran and apply alternative chemical compounds against flour beetles in these regions. Similar problems may happen in other parts of Iran, in future. Therefore, it is recommended to take precaution methods. 


\section{Literature}

Abbott, W. S. (1925): A method of computing the effectiveness of an insecticide. J. Eco. Ent., 18, $265-267$.

Ahuja, D. B. (1985): Cross-resistance characteristics of a laboratory selected pirimiphos-methyl resistant strain of Tribolium castaneum to some insecticides. J. Ento. Res., 9, 174-178.

Ameri Tourzani, S., Keyhanian, A. A., Marouf, A., Imani, S. and Sheikhi-Garjan, A. (2008): The susceptibility of different population of Tribolium confusum to malathion by bioassay technique. $18^{\text {th }}$ Iranian Plant Protection Congress, 24-27.

Arnaud, L. and Haubruge, E. (2002): Insecticide resistance enhances reproductive success in a beetle. Evol., 56, 2435-2444.

Bagheri Zenouz, E. (1986): Les animax nuisible aux produits entreposes. Vol.1. Les Coleopteres Depredateurs De Produits Alimentaires Et Industriels. Edition de Sepehr Tehran, Iran. 309 p.

Beeman, R. W. and Wright, V. F. (1990): Monitoring for resistance to chlorpyrifos-methyl, pirimiphos-methyl and malathion in Kansas population of stored product insects. J. Kan. Ent. Soc., 63, 385-392.

Calibosa, M. F., Sayoboc, P. D. and Amoranto, M. R. (1985): Pest problems and the use of pesticides in grain storage in the Philippines. ACIAR proceeding series. Australian Center for International Agricultural Research, 14, 17-29.

Gordon, L. and Snodgrass, G. L. (2008): Predicting field control tarnished plant bug (Hemiptera: Miridae) populations with pyrethroid insecticides by use of Glass-Vial bioassays. Southwes. Ent., 33, 181-189.

Halliday, W. R., Arthur, F. H. and Zettler, J. L. (1988): Resistance status of red flour beetle infesting stored peanuts in the South Eastern United States. J. Eco. Ent., 81, 74-77.

Haubruge, E., Amichot, M., Cuany, A., Berge, J. B. and Arnaud, L. (2002): Purification and characterization of a carboxylesterase involved in malathion-specific resistance from Tribolium castaneum (Coleoptera: Tenebrionidae). Ins. Bioch. Mol. Bio., 32, 1181-1190.

Jola, B. S. and Chawla, P. P. (1988): Comparative susceptibility of field population of Tribolium castaneum and Tribolium confusum from Panjab to malathion. J. Ins. Sci., 1, 193-194.

Loni, S., Farazmand, H., Sheikhi-Garjan, A. and Rafiei-Karahrodi, Z. (2010): Susceptibility of larval stage of T. confusum Duv. (Col.:Tenebrionidae) to IGR insecticides in vitro. J. Ent. Res., 2, 109-116.

SAS Institute Inc. (2002): SAS/STAT user's guide. Version 9.1. SAS Institute Inc., Cary, North Carolina.

Snodgrass, G. L. (1996): Glass-vial bioassay to estimate insecticide resistance in adult tarnished plant bugs (Heteroptera: Miridae). J. Eco. Ent., 89, 1053-1069.

Snodgrass, G. L. and Scott, W. P. (1999): A discriminating-dose bioassay for detecting pyrethroid resistance in tarnished plant bug (Heteroptera: Miridae) populations. Southwestern Ent., 24, 301-304.

Songa, J. and Rono, W. (1998): Indigenous methods for bruchid beetle (Col.: Bruchidae) control in stored beans (Phaseolus vulgaris L.). Int. J. Pest Man., 44, 1-4.

Taheri, M. S. (1994): The effect of temperature as a controlling factor of Tribolium confusum Duv. App. Ent. Phyt., 61, 52-60.

White, N. D. G. and Ben, R. J. (1988): Inheritance of malathion resistance in a strain of Tribolium castaneum and effects of resistance genotypes on fecundity and larval survival in malathion treated wheat. J. Eco. Ent., 81, 381-386.

Zettler, J. L. (1991): Pesticide resistance in Tribolium castaneum and T. confusum (Col.: Tenebrionidae) from flour mills in the United States. J. Eco. Ent., 84, 763-767. 